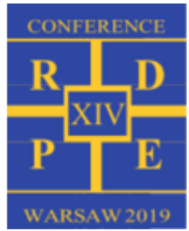

\title{
Analysis of long-term operation of the steam boiler live-steam outlet header and assessment of the feasibility of the header operation during accelerated start-ups
}

\author{
Bohdan Węglowski ${ }^{1,}{ }^{*}$, Marcin Pilarczyk ${ }^{1}$ \\ ${ }^{1}$ Institute of Thermal Power Engineering, Cracow University of Technology, Cracow, Poland
}

\begin{abstract}
The energy mix in most European countries is now characterized by a growing share of renewable energy sources (RES). The random nature of RES entails the need to balance the differences between the current amount of power generated in the system and the actual power demand. For this reason, power units incorporating steam boilers are most often operated under sub-peak rather than base load regimes. This creates many challenges to boiler operators due to the advanced age of the power units in service. In Poland, for instance, $77 \%$ of power units are more than 20 years old and $45 \%$ have been working for more than 30 years, which means that most of them are approaching their design life time. Further operation of these units requires a detailed analysis of the degree of wear of critical pressure components, including a thermal and mechanical stress-state analysis. The paper aims to present a methodology of wear degree calculations incorporated in the power unit control system. The performed calculations are based on real measurement data obtained from 8 months of operation of a boiler unit with the steam output of $650 \cdot 10^{3} \mathrm{~kg} / \mathrm{h}$. W ear degree calculations and a thermal and mechanical FEM -based analysis are performed to assess the possibility of shortening start-ups to address the dynamic requirements that power units operating in the Polish power generation system will have to meet.
\end{abstract}

\section{Introduction}

If much electricity is to be generated from renewable sources, wind power in the first place, due to the random character of RES-based production, the power system has to be provided with stable energy sources $[1,2,3]$. The effect of the obligation to adopt electricity generation from renewable sources is that a conventional power plant reserve capacity is held as a hot or a cold reserve, which means that boilers are kept in a standby mode, ready for a quick start-up, or they are shut down completely. In Poland, this role is played by centrally dispatched generating units (CDGU @). These are typically smallcapacity (200 M W) power units. However, there are more and more plants which, due to their large capacity, have been operating in base-load regimes and now are used for balancing the demand for electricity in the national power system. This is the effect of new highly efficient largecapacity supercritical power plants operating under the base load all year round. As their older power units operate with lower efficiency, the plants find it profitable to use them to satisfy the peak and sub-peak demand because it is possible to sell generated energy at higher intervention prices on the power market [4]. The operation of generating units in the power system involves the need to run start-ups as fast as possible. The other reasons for shortening the boiler start-up time are economic and ecological aspects. Considering that the boiler start-up process is carried out using heavy fuel oil (mazout), efforts are made to quickly achieve parameters that will make it possible to turn off the oil burners and use pulverised coal burners only. Consequently, the consumption of expensive mazout is reduced and start-up boiler's losses are minimized [5]. A nother important issue is limiting the emissions of pollutants arising when heavy fuel oil is fired. The pollutants do not pass through the flue gas purification system and get into the atmosphere directly.

Frequent shutdowns and start-ups, as well as subpeak and peak load operation of boilers involve degradation of their pressure elements, which shortens their life significantly. Issues related to the wear degree assessment are essential in terms of the safety of the boiler current operation and the possibility of extending the boiler safe operation beyond the design life.

\section{Calculation of the wear degree of a pressure element}

Each power boiler contains thick-walled pressure elements which determine their heating/cooling rates and the rate of load changes. In the case of subcritical steam boilers, the main critical elements are the drum and the live steam outlet header. The element selected for the analyses is the outlet header of a $5^{\text {th }}$ stage superheater of an OP-650 boiler, which is a very popular power unit in Poland. As the header operates in high temperatures, the element is affected by creep wear and, additionally, by low-cycle fatigue. The live steam outl et header is made of steel 10C rM 09-10 grade and is presented in Fig. 1. 


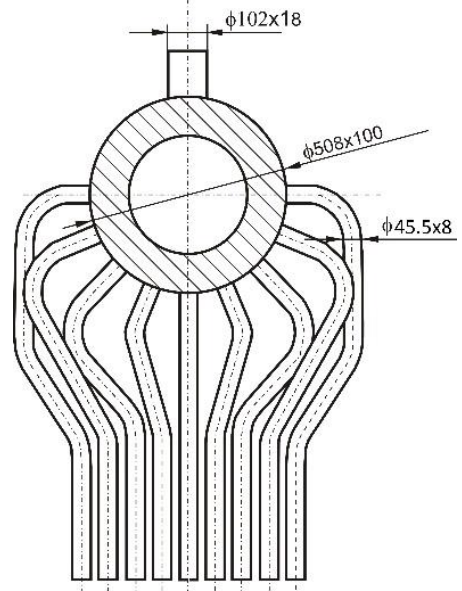

Fig. 1. Cross-section of the outlet header of the final stage $\left(5^{\text {th }}\right.$ stage) superheater of the OP-650 boiler

The header is a horizontal element with the following dimensions: length $-10,400 \mathrm{~mm}$, diameter $-508 \mathrm{~mm}$, wall thickness - $100 \mathrm{~mm}$ (cf. Fig. 1).

To demonstrate the method of calculating the wear degree caused by low-cycle fatigue, a long time of the boiler operation of 350,000 minutes ( 8 months) was selected for the analysis. The operating data obtained from the control system include temperatures measured on the outer surface of the outlet header and values of steam pressure. The data are presented in Fig. 2.

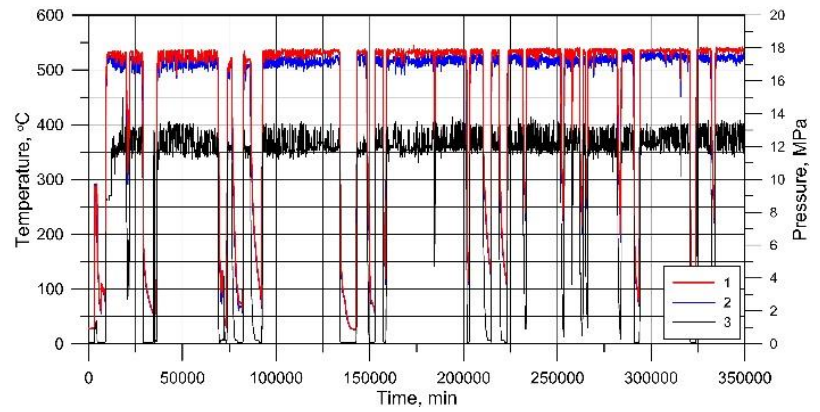

Fig. 2. Changes in the temperature of the live steam outlet header: header top (1); header bottom (2); changes in the header pressure (3)

During the period under analysis the boiler was started up 23 times (11 cold start-ups, 3 warm start-ups and 9 hot start-ups). Temperature was measured in seven points on the outer surface of half of the header perimeter. For better visibility only selected temperature measurements are presented in Fig. 2., i.e. on the header top (1) and bottom (2). To reconstruct the spatial-time temperature field in the cross-section of a pressure element, especially on its internal surface, a inverse heat conduction solution is applied, using measured temperatures on an easily accessible, insulated external surface. Then, it allows to calculate the distribution of thermal stresses and, after taking into account the change in factor pressure, to calculate the total thermal and pressure stresses. $[6,7,8]$

The data shown in Fig. 2 are used to calculate stresses in the header using an in-house program written in the Fortran environment. Fig. 3 and Fig. 4 illustrate axial and hoop (circumferential) stresses, respectively, on the header top and bottom inner surface for a cross-section not weakened by holes.

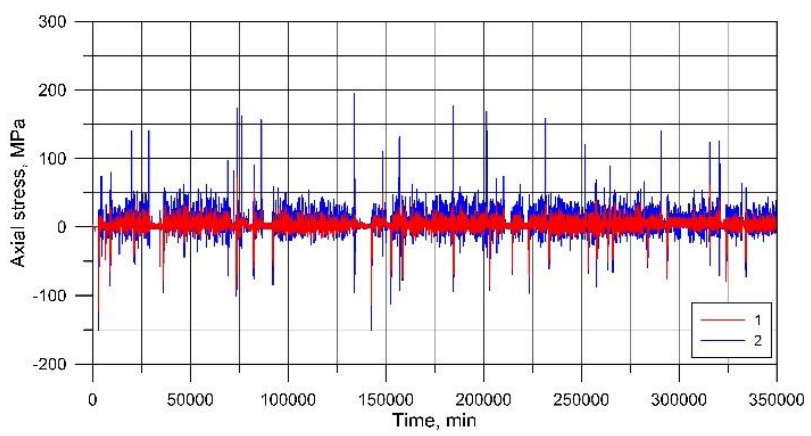

Fig. 3. Changes in axial stresses on the inner surface of the live steam outlet header: header top (1), header bottom (2)

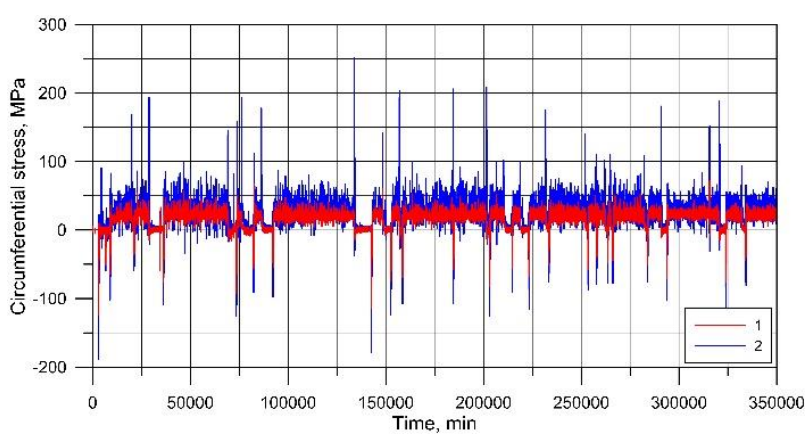

Fig. 4. Changes in hoop stresses on the inner surface of the live steam outlet header: header top (1), header bottom (2)

Fig. 3 and Fig. 4 indicate that axial stresses vary in the range of $-1+50 \mathrm{MPa}$, with the highest stress values reaching -150 to $200 \mathrm{M} \mathrm{Pa}$. The typical values of hoop stresses are included in the range of -50 to $100 \mathrm{M} \mathrm{Pa}$, and the maximum values reach -180 to $250 \mathrm{M} \mathrm{Pa}$.

\subsection{Wear degree due to low-cycle fatigue}

The wear degree related to low-cycle fatigue is calculated using hoop stresses because they are higher compared to axial ones. The outlet header load cycles calculated using the "rainflow method" [9] are shown in Fig. 5 and Fig. 6. Fig. 5 presents time-dependent values of the absolute sum of load cycle amplitudes $(2 \sigma)$ for measured operating data.

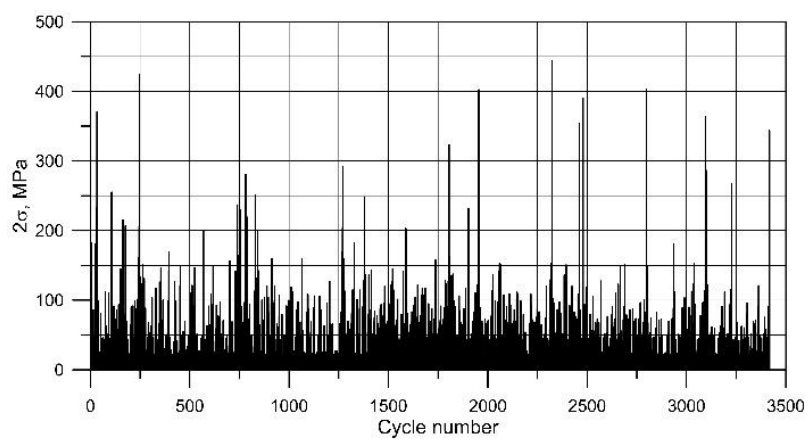

Fig. 5. L oad cycles of the live steam superheater outlet header 
To enable a fuller picture of the analysed element loading, load count calculations are carried out for cycles of 20 $\mathrm{MPa}$ and higher. In practice, cycles with the highest values are taken so that, taking account of the $20 \%$ error in low-cycle curves determination, the number of hours preceding the specimen rupture can be read from the chart. If the significant cycles were those with the value of $220 \mathrm{M} \mathrm{Pa}$ and higher, for the case under analysis there would be 24 such cycles and the calculated wear due to low-cycle fatigue would total 0.002 . It can be seen more clearly in Fig. 6, where the cycles are ordered from the biggest to the smallest.

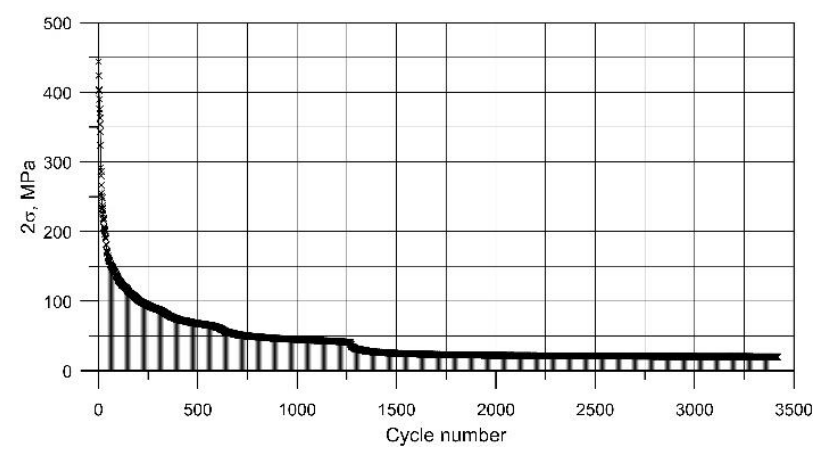

Fig. 6. Biggest-to-smallest load cycles of the live steam superheater outer header

Linear summation hypothesis is used to take account of the variable amplitude: for the amplitude of $2 \sigma$ the number of cycles $N_{d j}$ is determined at which the element destruction occurs. If the number of cycles with the doubled amplitude $2 \sigma$ (cf. Fig. 7) is $n_{j}$, the element wear degree due to low-cycle fatigue totals:

$$
D_{z}=\sum_{j=1}^{N_{z}} \frac{n_{j}}{N_{d j}}
$$

Fig. 7 presents characteristics of low-cycle fatigue strength of ferritic steel for the room temperature of $20^{\circ} \mathrm{C}$ and for the temperatures of 100 to $600^{\circ} \mathrm{C}$ every $100^{\circ} \mathrm{C}$.

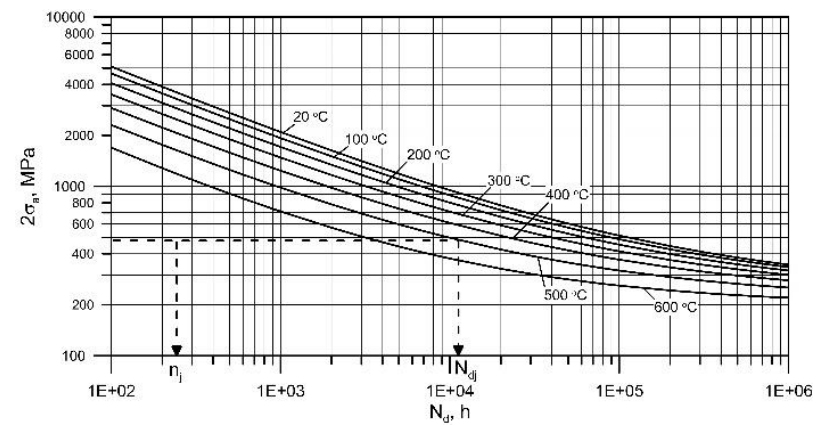

Fig. 7. Characteristics of low-cycle fatigue strength of ferritic steel

Fig. 7 presents an example of determining the number of cycles to destruction $N_{d j}$ at known operating parameters: temperature and load $2 \sigma_{a}$. In these conditions the element is subjected to $n_{j}$ cycles. Knowing the value of stresses arising during the operation of the power unit elements, it is possible to determine their load cycles and, based on that, to read from the chart or, if the characteristics of wear due to low-cycle fatigue are defined by equations, to calculate the time to destruction for individual cycles and the load share in the loss of life using formula (1).

\subsection{Wear degree due to creep}

Creep-related fatigue is cal culated using the time-todestruction dependence on loads in operating temperatures higher than the limit point for the steel grade the element is made of. A relevant chart for 10C rM 09-10 steel is shown in Fig. 8.

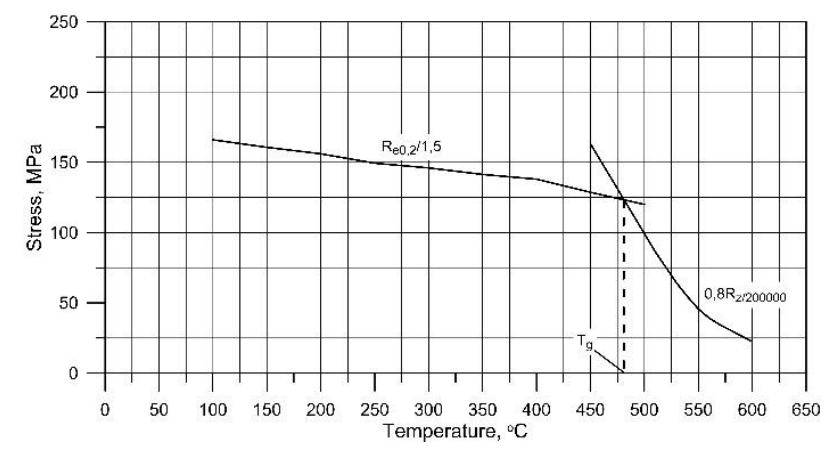

Fig. 8. Determination of limit temperature $\mathrm{T}_{g}=480{ }^{\circ} \mathrm{C}$ for 10C rM 09-10 steel, data to find the yield point at elevated temperatures $R^{t} 0.2$ and creep strength over time $R_{t z / 200000 ;}$ devel oped based on [10]

If creep-related destruction is calculated according to the recommendations of Standard EN-12952-4 [11], in the case of elements with the wall thickness similar to the walls of the analysed component, i.e. $100 \mathrm{~mm}$, using plane stresses calculated in the same manner as for thin-walled vessels, at the design pressure value of $16.2 \mathrm{MPa}$, gives stress values lower than $50 \mathrm{MPa}$. Elements operating in temperatures close to $540^{\circ} \mathrm{C}$ and under loads smaller than $50 \mathrm{MPa}$ can operate without any time limits. This is demonstrated by the chart presented in Fig. 7 illustrating creep strength depending on the time to rupture for 10CrM 09-10 steel.

Considering the real time of a pressure element operation $t_{k}$ and using the creep strength chart for a given steel grade to find time $t_{d k}$, after which the specimen is ruptured, the element wear degree caused by creep is determined using the following relation:

$$
D_{p}=\sum_{k=1}^{N_{p}} \frac{t_{k}}{t_{d k}}
$$

where $N_{p}$ - number of time intervals.

Utilizing stress monitoring systems, it is possible to determine creep-related wear more precisely using calculated hoop stresses (cf. Fig. 7). For the final steam outlet header of the OP-650 boiler, creep-related wear for the presented time of operation totals 0.0117 ; the wear degree due to low-cycle fatigue is 0.002 .

The design remnant life is determined using the Palmgren-M iner relation: 


$$
\sum_{j=1}^{N_{z}}\left(\frac{n}{N_{d}}\right)_{j}+\sum_{k=1}^{N_{p}}\left(\frac{t}{t_{d}}\right)_{k} \leq D
$$

where:

$D$ - total damage due to fatigue and creep, $n$ - number of cycles at $j^{\text {th }}$ loading conditions, $N_{d}$-number of allowable cycles of changes in loads at $j^{\text {th }}$ loading conditions, $t-$

time of the load duration at $\mathrm{k}^{\text {th }}$ conditions, $t_{d}$-allowable time of static load duration at $k^{\text {th }}$ loading conditions.

According to the Palmgren-Miner hypothesis, the element total wear due to low-cycle fatigue and creep is thus equal to 0.0137 . The time of operation in creep conditions, i.e. in temperatures higher than $400^{\circ} \mathrm{C}$, is 273,000 hours. For the temperature higher than the limit point $T_{g}=480^{\circ} \mathrm{C}$, the calculations are carried out using momentary creep strength for 10C rM 09-10 steel reduced for safety reasons by $20 \%$; for the temperature lower than $T_{g}$ - the yield point reduced by the safety factor of 1.5.

If operation was continued in the same conditions as in the period under analysis, i.e. if the temperature level allowable for the steel was not exceeded and, considering the long start-up times, thermal stresses were low, the element could operate for another 37.8 years. Taking account of $0.6 t_{r}\left(t_{r}-\right.$ remnant resistance to creep-related wear) to determine component service life [12], i.e. taking account of the time corresponding to the end of the secondary creep stage and the wear degree due to lowcycle fatigue, the time of further and safe operation is about 22 years. This is about 192,200 hours of operation. Because the estimation concerns the time of safe operation of an element weakened by holes, taking account a safety factor of $30 \%$, the time of safe operation totals 147,850 hours. This time, assuming the boiler appropriate operation and considering such a low degree of wear, is close to the expected value because for new shell-and-hole el ements designers set it at 140,000-240,00 hours.

\section{ASSESSMENT OF THE FEASIBILITY OF THE HEADER OPERATION DURING ACCELERATED START-UPS}

The assessment of the feasibility of the header operation during accelerated start-ups was performed within collaboration between the Cracow University of Technology and a Polish power plant. As no operating characteristics had been provided by the boiler manufacturer, the authors developed reference start-up curves for the cold, warm and hot start-up and their counterparts for the start-up time shortened by $20 \%$ and $40 \%$. The developed curves define allowable changes in live steam temperature in the outlet header and in pressure in the boiler drum as a function of time. The start-up curves are presented in Fig. 9. The start-up of approx. 300 minutes ( 5 hours) is adopted as the reference start-up procedure. Each developed curve takes account of the necessary time of 10 minutes for the steam turbine preparation at the beginning of the procedure. For each proposed start-up curve, a transient thermal and structural
FEM-based analysis is performed using the Ansys Mechanical APDL software.

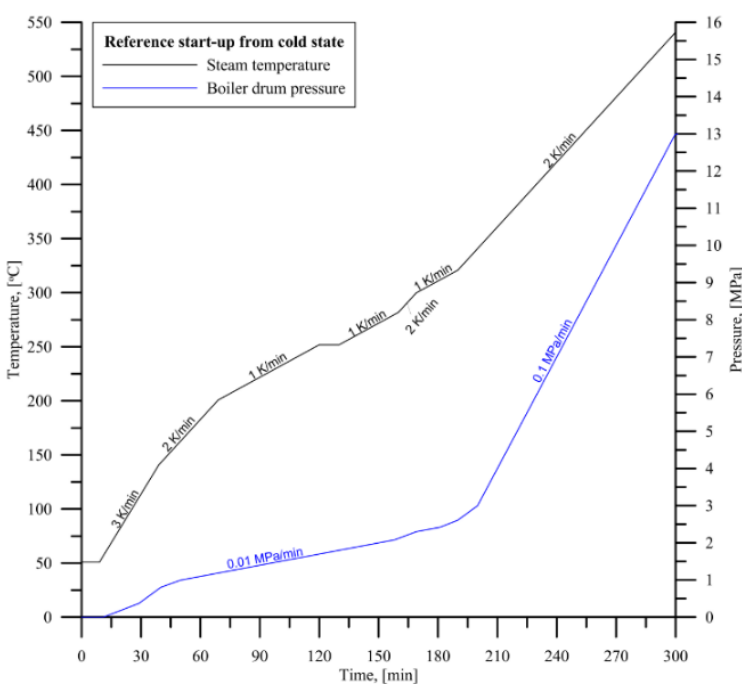

Fig. 9. Cold start-up curves for the OP-650 power unit

The numerical model is developed based on the outlet header technical documentation and the final number of finite cells satisfies the mesh sensitivity analysis. Fig. 10 illustrates the transient temperature distribution within the component during the heating process. Temperature gradients such as the ones observed in Fig. 10 cause high thermal stresses, especially in stress concentration zones on the inner surface of connector pipes

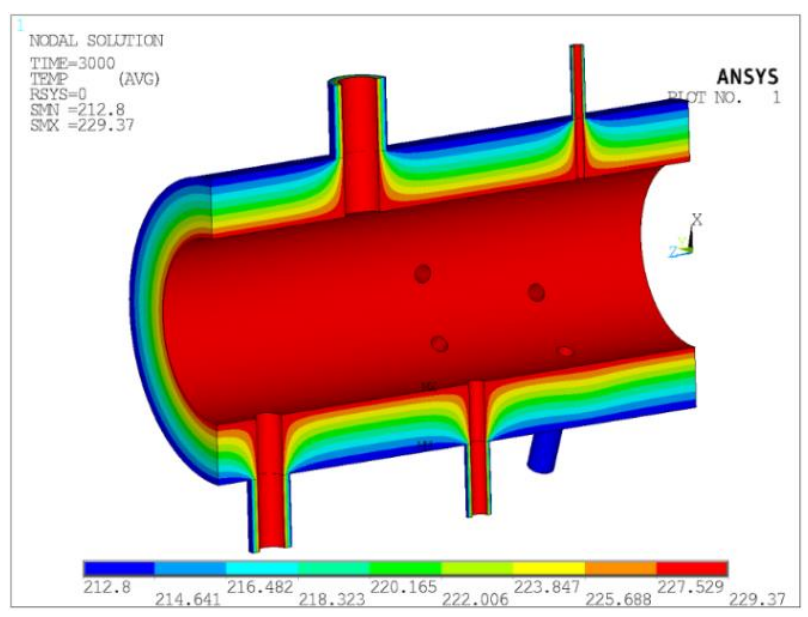

Fig. 10. Transient temperature field within the outlet header during the start-up procedure calculated using the FEM -based ANSY S M echanical APDL program (heating rate: $3.33 \mathrm{~K} / \mathrm{min}$ )

The finite element method enables an analysis of total stresses occurring within the header wall. Changes in the hoop (circumferential) and axial stresses on the header inner surface during cold start-up sequences are presented in Fig. 11. A nalysing Fig. 11, it can be seen that a decrease in the start-up time causes significantly higher thermal stresses at the beginning of the heating process. At the end of the start-up procedure, the stress values are similar because temperature gradients approach zero and stresses are only induced mechanically by internal pressure. Higher stress values can be observed on the edge of the hole created by the connector pipe. Generally, headers 
embedded in the steam boiler are equipped with many connector pipes which deliver superheated (or reheated) steam from the superheater subsequent stages.

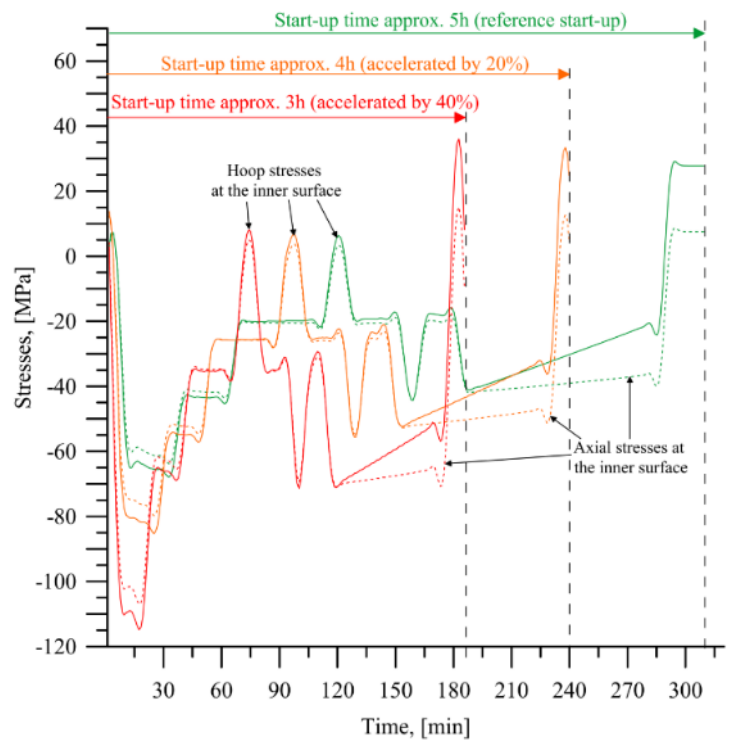

Fig. 11. Changes in hoop and axial stresses on the inner surface not weakened by a connector pipe

In the analysed case, the most common connector pipe has the outer diameter of $45.5 \mathrm{~mm}$ and the wall thickness of 8 $\mathrm{mm}$. The changes in hoop and axial stresses determined during the start-up sequences are presented in Fig. 11 and Fig. 12, respectively. Fig. 11 and Fig. 12 indicate that the stress values are significantly higher compared to those on the inner surface, and axial stresses take slightly higher values. Typical stress values vary between -100 and 80 $\mathrm{M} \mathrm{Pa}$ for the reference start-up, and between $-130 / 80$ and $-170 / 80 \mathrm{M} \mathrm{Pa}$ for start-ups shortened by $20 \%$ and $40 \%$, respectively.

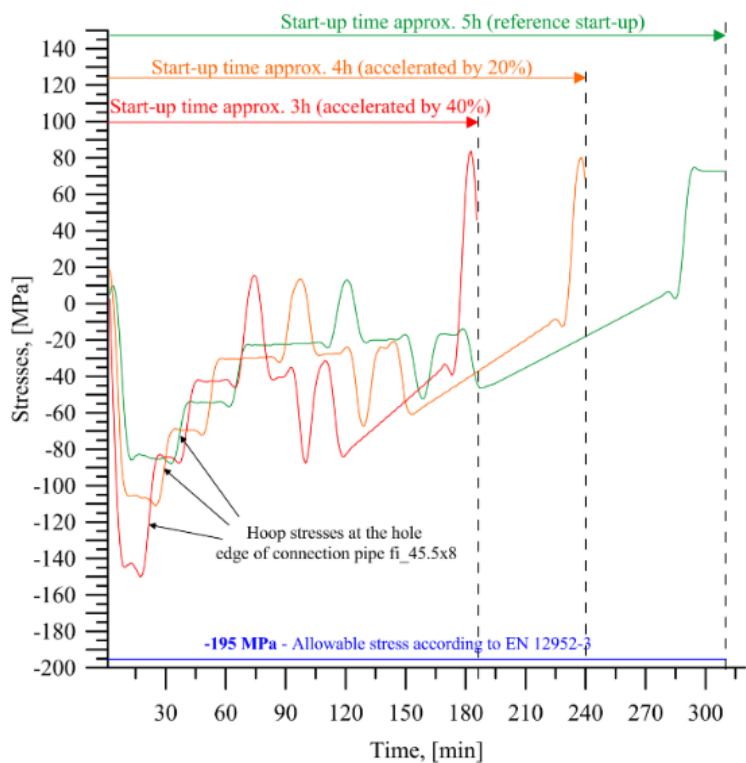

Fig. 12. Changes in hoop stress values on the edge of the hole of a $\varnothing 45.5 \times 8$ connector pipe according to the proposed start-up curves

N one of the values exceed the allowable stress determined for the case under consideration (outlet header $\& \varnothing 45.5 \times 8$ connector pipe) based on the EN standard [13]. The analysis results indicate that there is a margin for shortening the reference start-up sequences, at least from the point of view of thermal stresses. V ery similar results were obtained for another critical component, i.e. the boiler drum.

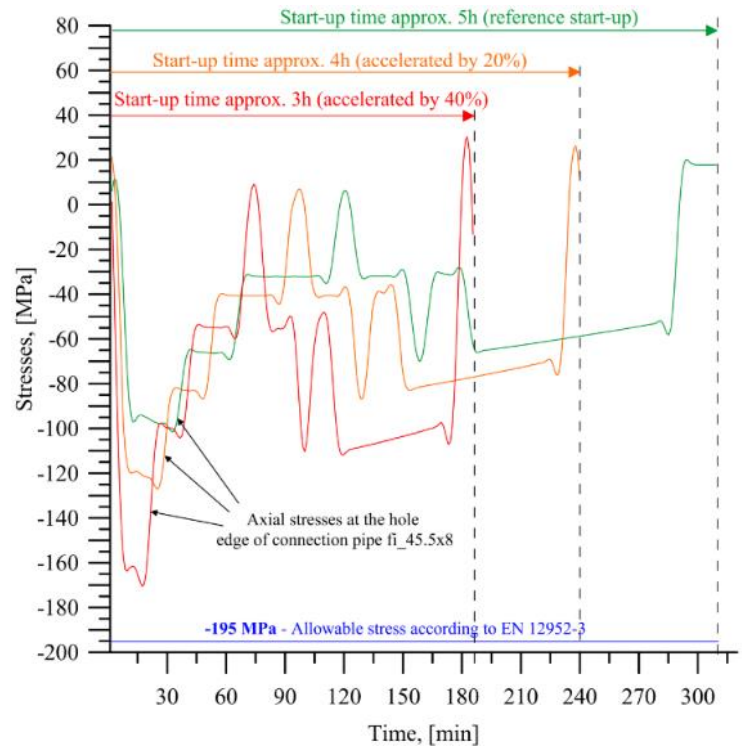

Fig. 13. Changes in axial stress values on the edge of the hole of a $\varnothing 45.5 \times 8$ connector pipe according to the proposed start-up curves

However, their presentation is beyond the scope of this paper. Although the analysis results can be valuable for boiler operators, the final effect in the form of an improvement in the steam boiler dynamics (i.e. accelerated start-ups) depends on the technical condition of the boiler itself and the auxiliary components (coal mills, air fans, feed pumps, etc.).

\section{Conclusions}

Assessing the time of further safe operation of elements, it is necessary to take account of their wear degree. It should also be noted that damage to pressure elements is not only caused by creep and low-cycle loads. The thermal shocks that affect horizontal thick-walled pressure elements of power boilers cause not only local cracks in the area of connector pipe holes but also bending in the horizontal axis. The thermal shocks arising during the boiler hot start-up can be an effect of the pumping of the cooler condensate accumulated in superheater coils, bad dewatering or water leaks from the valves of steam attemperators. Power stations and combined heat and power plants must be safe, reliable and efficient, and their operating costs should be as low as possible. It is therefore extremely important that areas which are especially prone to damage should be identified correctly. It is also essential to monitor stresses arising in critical elements during the boiler operation. The issues are topical not only because of the frequent changes in loads and the shutdowns and start-ups of power boilers but al so due to the current trend aiming to lower the boiler technical 
minimum. It is therefore of the utmost importance to ensure a high level of operating saf ety, a measure of which can be the technical risk related to the operation of a power unit or facility. The presented issues can be of help in the operation of boilers and turbines of power units which are already in service and in the design of new coalfired supercritical power units.

\section{References}

1. Rao, K.R. Wind Energy for Power Generation, Meeting the Challenge of Practical Implementation Springer, 2019

2. K ato T. Prediction of wind power generation output and network operation, chapter 5 Integration of Distributed Energy Resources in Power Systems, Edited by: Funabashi, ScienceDirect, 2016

3. Taler J., Węglowski B., Cebula A., An assessment of Polish power, M odern Power Systems, vol. 27 No. 5, pp. 13-17, M ay 2007.

4. European Network of Transmission System Operators for Electricity ENTSOE, Power in Transition, R\&I Roadmap 2017-2026, 2017.

5. Taler, J., Węglowski, B., Taler, D., Sobota T., Dzierwa, P., Trojan,M., Madejski, P., Pilarczyk M.: Determination of start-up curves for a boiler with natural circulation based on the analysis of stress distribution in critical pressure components. Energy, vol. 92, 2015, str. 153-159.

6. Pilarczyk M., Węglowski B., Determination and validation of transient temperature fields within a cylindrical element using the inverse heat conduction method, Applied Thermal Engineering 150 (2019) pp.1224-1232

7. Węglowski B., Pilarczyk M., Experimental and numerical verification of transient spatial temperature distribution in thick-walled pressure components, Journal of Mechanical Science and Technology 32 (3) (2018) pp. 1087-1098

8. Taler J., Dzierwa P., Jaremkiewicz M., Taler D., K aczmarski K., Trojan M ., W ęglowski B., Sobota T., Monitoring of transient $3 D$ temperature distribution and thermal stress in pressure elements based on the wall temperature measurement, Journal of Thermal Stresses, 2019, Vol. 42, N 0. 6, 698-724

9. Murakami Y., The Rainflow Method in Fatigue, Butterworth-Heinemann, 1992.

10. EN 10216-2, Seamless steel tubes for pressure purposes - Technical delivery conditions - Part 2: Non-alloy and alloy steel tubes with specified elevated temperature properties.

11. EN 12952-4, Water-tube boilers and auxiliary installations - Part 4: In-service boiler life expectancy calculations.

12. Dobrzański J., Materials science interpretation of the life of steels for power plants, Open Access Library, Volume 3, 2011.

13. EN 12952-3 : 2011 Water-Tube Boilers and Auxiliary Installations - PART 3: Design and Calculation for Pressure Parts of the Boiler 